\title{
MEGALOPOLISES GEOTECHNICS
}

\author{
Vladimir Makarov ${ }^{1 *}$ and Valery Makishin ${ }^{1}$ \\ ${ }^{1}$ Far Eastern Federal University, Vladivostok, Russia
}

\begin{abstract}
Annotation. Necessity of formation of the uniform concept of maintenance of development of the megalopolises, combining building of aboveground and underground complexes is shown. Interaction of elements of geotechnical system «a megalopolis - an underground construction» with a view of maintenance of ability to live of underground constructions of megalopolises is considered. Classification of conditions of development of megalopolises by stage of use of the underground space, added with criteria of reliability, safety and an economic optimum is developed. Conditions of maintenance of ecological compatibility and infrastructural appeal of megalopolises, as centres of cultural and commercial development are considered. Necessity of formation of the general scientific discipline «Megalopolises Geotechnics», covering a complex of methods of aboveground and underground building of megalopolises taking into account reliability and safety of functioning, ecological compatibility, infrastructural appeal, and also an economic optimality answering to criterion is formulated.
\end{abstract}

\section{Introduction}

Development of megalopolises in modern conditions demands a comprehensive approach considering both the characteristics aboveground, and underground building, bound among themselves principles of reliable and safe functioning at the optimum economic decision Such approach in case of a megalopolis locating in island terrain where the aboveground space is circumscribed by the connatural factor - a coastal line is especially important. If thus the terrain has a mountainous relief without use of underground space a big city it is simple cannot be developed effectively [1].

Thus, classification of conditions of building by principles of a sustainable development [2] becomes the important factor of regulation of use of underground space of megalopolises. Among the most important requirements it is necessary to note peak efficiency of building of a construction (its reliability, safety, ecological

*Corresponding author:vlmvv@mail.ru 
compatibility, and also infrastructural appeal). Other principle it is maximum an effective utilisation of underground space (compactness of a locating of underground constructions in relation to each other and terrestrial surface at observance of the first principle). Both first conditions should answer also to a principle of the minimum cost of building.

Definition of the specified principles shows that the existing contradiction between requirements of the minimum cost and peak efficiency leads to a problem of optimization, which should be resolved in each specific case with application of classification and mathematical approaches.

\section{Interaction of aboveground and underground building complexes}

To one of the major aspects of operation of underground constructions of different function is maintenance of their interaction with objects a terrestrial surface. For maintenance of it process carrying out of auxiliary developments of different function transport (escalators, ladders, foot tunnels, motor transportation inclined developments for maintenance of ability to live of objects of welfare, industrial appointment, a warehouse economy) is necessary; power supply (cable tunnels and chinks); ventilations; water drains and water removals.

At designing and building of city underground constructions, it is necessary to consider that the underground construction is operated in the conditions of its interaction with a city infrastructure on the terrestrial surface, existing underground communications of different function both mountain-geological and geomechanical conditions of a soil and rock massif. Underground objects in a combination to objects on a terrestrial surface provide building of a complex infrastructure that in modern social and economic conditions is a necessary condition of functionality of a city infrastructure as a whole. Thus, as a rule, optimum conditions of formation of underground transport and foot paths with the minimum height of movings on a vertical $[3,4]$ are provided.

By researches, it is positioned that limiting extent of transport-ventilation and other auxiliary openings of various section confines their admissible component within 15-20 $\%$ from volume of an underground construction and size of aerodynamic resistance of a ventilating network of an underground construction.

The lobe of these openings can be increased to $30-37 \%$ in case of continuous development on the area and in depth of a soil and rock massif of geotechnogenic underground space [5]. It follows from this that economically effective volume of an underground construction assumes its continuous development for the purpose of optimisation of technological and logistical communications between a megalopolis and underground constructions.

At the initial stage of formation of uniform geotechnological system each separate underground construction can depend in full or in part on maintenance from a terrestrial surface. It, taking into account an admissible lobe of developments of auxiliary appointment, assumes building of shallow underground constructions with rather small volumes.

At a substantiation of a configuration of underground object it is necessary to consider that for high-grade functioning of an underground construction its maintenance 
with fresh air according to the positioned norms is necessary. Feature of underground constructions is necessity of constant illumination of developments and air conditioning in them. The large underground object is the complex power consumer demanding presence of powerful systems of constant and emergency power supply. Appointment, the dimensions of an underground construction, hydro-geological conditions of a soil and rock massif and a profuseness of deposits demand building of powerful system of the water drain and water removal. In this connection one of priority problems of Megalopolises Geotechnics is the establishment of laws and communications in geotechnical and geotechnological systems, making system «an underground construction - a city infrastructure» [6].

Gradual development of an underground infrastructure assumes dilating of developments on the area and in depth of the given mountain tap taking into account influence of objects of a terrestrial surface and geomechanical characteristics of a soil and rock massif.

In process of development of this system there is an affiliation by a series of the located underground constructions of different function in the uniform system, allowing to tolerate from a terrestrial surface to underground developments not only objects of welfare, technological, industrial and power appointment, but also to incur functions of maintenance of objects of a city infrastructure.

Development of underground geotechnological logistical systems of underground space makes essential impact on formation of an infrastructure of a megalopolis. Conduction to underground developments of objects of material and power supply allows to make rational layout decisions of placement of buildings and the constructions most of different function in the most necessary places for a city, including in the conditions of the extremely constrained building, to reconstruct a transport network taking into account constantly increasing transport streams, to create and develop underground transport, both the railways, and undergrounds, to optimise parametres of development of city engineering networks, to provide decrease in consumption of fuel and energy resources and to promote decrease in negative influence on city ecology [3, $4,6]$.

Modern explorers notice that on the one hand, the underground space of megalopolises and cities-companions by their consecutive development on the area and in depth of hills, affiliation of close located underground complexes in uniform supersystem practically has no restrictions.

But, as well as any complex system, it as becomes to vulnerable and subject system failures [5]. In this connection carrying out of the researches defining at a modern level of development technicians and technologies of optimum design data of a uniform geotechnological complex taking into account their area, number of storeys, appointments, completeness of use, influence on formation, maintenance and development of objects of a city infrastructure of a megalopolis for the purpose of rational geographical demarcation of underground space and specialisation of underground constructions is necessary.

The major part of strategy of transferring from traditional aboveground building to underground is geographical demarcation of underground space, applicable for building. For this purpose it is necessary in reacting documents on working out of the general layout of a city (on long-term prospect) to lead a condition of conducting works on a complex assessment of development of underground space along with a traditional complex assessment of city lands and terrains adjoining to it. 
The complex assessment of development of underground space is manufactured on the basis of the detailed analysis of underground space of a city. Characteristic regions precipitate out, considering not only functional features of the yielded field of a city, but also geological, hydro-geological and other conditions in which building and operation of the future underground constructions will be carried out.

\section{Completeness of use of underground space of the Vladivostok City}

The research made within the framework of complex development of underground space of the Vladivostok City, consists in working out of procedures of definition of rational parametres of underground constructions taking into account their interference and means of maintenance of the working space. The procedure should solve the questions bound with three last from above-stated directions of procedure of structurization are space-planning, constructive and technological decisions.

Definition of the minimum dimensions of pillars between openings it is manufactured taking into account functional features of rocks of constructions erected in the rock massif, i.e. completeness of use of underground space should not depend on that in the congenial, normal or preferable regions building of those or other constructions [3] is supposed. Finally completeness of use of underground space will be defined by optimum distances between openings (safety pillars) which are in turn defined by stress concentrations in pillars and strength properties of rocks.

Completeness of use of underground space on conditions of a stressed state of rocks can be divided into three conditional categories $\left(\sigma_{c}-\right.$ ultimate strength of containing rocks on axial compression):

1. Safe - at which dimensions safety it is whole get out of a condition that stress concentration in them will not exceed $0.5 \sigma_{c}$;

2. Centre stage of danger - at which strains in pillars are in limens $0.5-0.8 \sigma_{c}$;

3. Dangerous conditions - at which strains are in limens $0.8-0.9 \sigma_{\mathrm{c}}$.

Definitions of the minimum dimensions of safety pillars it is whole, providing the set safety factor can be carried out with use of a design procedure of strains in a rock massif around interacted openings [7]. In this case the concept of quotient of completeness of use of underground space is introduced:

$$
K_{\Pi \Pi}=\frac{V_{\Pi C}}{V_{0}},
$$

where $V_{\Pi C}$ - volume of an underground construction,

$V_{0}$ - total amount applicable for building of underground space.

The check point augmentation at invariable values $V_{0}$ has the big economic value as descends at the expense of involving in economic circulation of additional volumes of underground space. 


\section{Classifications of conditions of development of megalopolises by conditions of interaction of aboveground and underground parts of a city}

The considered problems demand introduction of classification of conditions of development of megalopolises on stage of use of the underground space, answering to the above resulted principles. Three cores of a case of interaction of abovegroundunderground development of a megalopolis precipitate out. First, it is conditions of local placement of the underground construction bound exclusively with any one object, placed on a terrestrial surface. Secondly, conditions independent of functioning of objects of aboveground building of "an Underground City». And thirdly, conditions «Integrated aboveground-underground» developments of the megalopolis representing a uniform complex. Each of the considered divisions has it's one the advantages and disadvantages. So, local building of underground constructions provides peak efficiency of operation of objects of aboveground and underground building at minimisation of extent of auxiliary openings. But thus use of underground space of a megalopolis not effectively, and frequently and simply is not considered. Also efficacy of building for a city as a whole is not considered.

The concept of an "Underground City» means possibility of independent coexistence of a aboveground part of a megalopolis and its underground part. Advantages of such variant of development is possibility of effective operation of an underground part of a megalopolis, relative simplicity of building and minimisation of costs on maintenance of communication with a surface. Disadvantages consist in necessity of carrying out of additional underground communications and auxiliary openings, difficulty of maintenance of a reliable communication of underground and aboveground objects.

The variant «Integrated aboveground-underground» megalopolis developments in many cases is preferable, allows to aggregate advantages of first two considered cases. However, it has such negative sides, as complication of technical decisions of building.

\section{Discussion}

The resulted classification of conditions of a sustainable development of megalopolises in aggregate with the specified principles developments and criteria of reliability and safety of functioning, ecological compatibility, infrastructural appeal, and also criterion of an economic optimality compound a basis of a scientific discipline «Megalopolises Geotechnics» which urgency of formation is confirmed by modern practice [8].

Main ideas have been discussed at the International Geotechnical Conference "Geotechnical Challenges in Megacities" (Moscow, 7-10 June 2010), where the many practical decisions had been done [9]. The article is widening the Conference recommendation and introducing the approach to the "Megalopolises Geotechnics" formation.

\section{Conclusion}

Problems of interaction are relevant for geotechnics of megacities. Interaction of foundations, effect of new buildings and constructions on underground structures along 
with an effect of new underground structures on existing buildings and networks - all that problems are already within the range of interests of geotechnical engineers and must attract even more attention in the practise. Systems approach to these problems dictates the necessity to both geofailures and geological risks assessment in urban planning. The latter is often related with construction on problematic soils and rocks.

Many megacities were formed on the island territories. The need to take in account the surface limit and mountain like form of relief causing difficulties for geotechnical engineers. Another feature of prolonged human activity in built-up areas is pollution of the environment, giving rise to geoecological problems of construction on contaminated soils. Preservation of hydrogeological situation in course of underground space development, water pumping and other man-caused effects lies within the same range of problems.

The complex of the practical geoengineering decisions can be achieved on the way of the "Megalopolises Geotechnics" formation.

The research is supported by a grant from the Ministry of Science and Higher Education of the Russian Federation No. RFMEFI58418X0034.

\section{References}

1. Makarov V., Anikeev V., Pushkarev I., Sadardinov I., \& Mirobian A. Procedia Engineering, 165, 497-503. (2016). DOI: 10.1016/j.proeng.2016.11.725

2. Porfiryev, B. N., AND Bobylev, S. N. Studies on Russian Economic Development, 29 (2), 116-123. (2018).

3. The Management on complex development of underground space of big cities V.A.Ilyichev, G.E.Golubev, A.V.Zamaraev, A.N.Skachko, O.I.Ignatov, V.G.Budanov, O.N.Korotkov. (2004). http://rykovodstvo.ru/exspl/31572/index.html (in Russian)

4. Korchak, A. V. Problems, directions and paths of problem solving of development of underground space of megalopolises / A. V. Korchak//the Mining information-analytical bulletin.. 5. pp. 89-98. (2014) (in Russian)

5. Mining sciences. Development and conservation of bowels of the Earth / the Russian Academy of Sciences, АГН, the Russian Academy of Natural Sciences, МИА; under the editorship of K.N.Trubetsky. Publishing house AGN. 478 with. (Mining Sciences. Development and Conservation of Mineral Resources of the Earth/RAS, AMS, RANS, IEA; Under General Editorship of K.N. Trubetskoy.-M.: Academy of Mining Sciences, Publishing House. 478 p.). (1997) ISBN 5-7892-0008-7 (in Russian)

6. Makishin, V.N. Methodology of a substantiation of rational parametres of transport developments of underground constructions / V.N.Makishin, A.A.Fatkulin, B.F.Lesovsky. Vladivostok: Publishing house DVGTU. 157 p. (2007) (in Russian)

7. Fotieva N.N., A.N.Kozlov Fix parallel openings in seismic countries. Nedra. 231 p. (1992). (in Russian)

8. Makarov V. Island Megalopolises: Tunnel Systems as a Critical Alternative in Solving Transport Problems. Engineering, 4 (1), 138-142. doi.org/10.1016/j.eng.2018.02.001

9. "Geotechnical challenges in megacities". Proceedings of the International geotechnical conference. V.1, M.: Edited by V.P. Petrukhin, V.M. Ulitsky, I.V. Kolybin, M.B. Lisyuk, M.L. Kholmyansky. 392 p. (2010) 